Article

\title{
Extraction of Metal Arsenic from Waste Sodium Arsenate by Roasting with Charcoal Powder
}

\author{
Kang Yang ${ }^{\mathbb{D}}$, Wenqing Qin ${ }^{(1)}$ and Wei Liu * \\ School of Minerals Processing and Bioengineering, Central South University, Changsha 410083, China; \\ csuyangkang@163.com (K.Y.); qinwenqing@csu.edu.cn (W.Q.) \\ * Correspondence: ase.6520@163.com; Tel.: +86-137-8700-7421
}

Received: 25 June 2018; Accepted: 11 July 2018; Published: 13 July 2018

check for updates

\begin{abstract}
The current paper explored the directly reductive decomposition of waste sodium arsenate by roasting it with charcoal powder to volatilize less toxic $\mathrm{As}^{0}$ and to simultaneously obtain sodium salts with potential commercial value, serving the purpose of developing a more sustainable route to deal with the environmental issues faced by the antimony production industry in China. The process was firstly evaluated by thermogravimetric (TG) analysis and thermochemical calculations. The effects of $\mathrm{N}_{2}$ flow rate, roasting temperature, dosage of charcoal powder, and roasting time were then investigated. The results showed that the arsenic extraction could reach $99.84 \%$ under optimal conditions. The roasting residue, containing arsenic as low as $0.0598 \%$, was a promising source for the production of $\mathrm{Na}_{2} \mathrm{CO}_{3}$ as expected. In addition, X-ray diffraction (XRD), scanning electron micrograph (SEM), and X-ray photoelectron spectroscopy (XPS) were conducted to reveal the roasting mechanism and formation of metal arsenic was thereby confirmed.
\end{abstract}

Keywords: arsenic; arsenic removal; arsenate; metal arsenic; reductive roasting

\section{Introduction}

Arsenic, a well-known poison, carcinogen, and perhaps teratogen, has once found widespread use in agriculture (pesticides, herbicides, etc.) and industry (the production of lead car batteries, of anti-friction agent in bearings, etc.) [1], but due to its potential threats to public health, its global consumption has declined as many countries have banned the use of arsenic-containing agricultural products [2]. The policy intends to control arsenic-related environmental risks by putting restrictions on its application, whereas new challenges emerge elsewhere as more and more arsenic wastes are generated from other anthropogenic activities, especially in the fields of mineral processing and metallurgy, as arsenic is one of the common elements distributed in the earth's crust.

In China, about 5000 tons of waste mainly bearing arsenic and antimony, known as arsenic-alkali residue (AAR), is produced annually from antimony extractive metallurgy in addition to a total storage of 200,000 tons [3-5]. The rapidly increasing amount of the residue has posed a serious burden on its management and thus has resulted in a series of research regarding its treatment. In order to recover antimony, arsenic is usually separated from the AAR, resulting in the overproduction of sodium arsenate which had already been in huge stockpile because of a shrinking market. The maintenance of such hazardous waste is highly risky due to its solubility and toxicity, and it is now urgent to develop an adequate route for its further disposal.

The advancement on the treatment of arsenic wastes has been reviewed by several researchers [6-9], and one can notice that, because of lack in economical motivation, efforts are seldom put on its recovery. Instead, a lot of work has been carried out to stabilize arsenic in order to reduce its mobility. The objective is to prevent arsenic from diffusing into the adjacent surroundings as it will finally report to the landfills. Given the wide range of chemical characteristics of arsenic wastes, 
the stabilization/solidification (S/S) process, recognized by United States Environmental Protection Agency (USEPA) as "the best demonstrated available technology" for land disposal of most toxic elements, is suggested to be used on a case by case basis [9]. In the case of the waste sodium arsenate (WSA), only a few reports are available. In these studies, WSA is either reacted with ferric to form scorodite [10], a stable compound of arsenic with the lowest solubility and dissolution rate among common arsenic minerals [11], or is fixed with cement via S/S [1,12].

In general, these reports have actually suggested that the options are limited to solidify the arsenic waste before its final land disposal. In addition, it is recommended that, since arsenic (V) is less toxic than arsenic (III) [13], pre-oxidation of arsenic (III) waste appears to be the best solution prior to an S/S process [14]. Therefore, it is unsurprising to find that focus has barely been put on another direction which may prove worth exploring, that is, to reduce arsenic into its elemental phase.

As a matter of fact, there are at least two benefits for treating WSA by reduction. Firstly and most importantly, the amount of WSA could be minimized once it is converted into metal arsenic (ideally, 1 ton of sodium arsenate could produce only about $177 \mathrm{~kg}$ metal arsenic). This basically indicates the maximum of waste minimization on WSA as there are no other arsenic species more "minimal" than $\mathrm{As}^{0}$. Secondly, the formed metal arsenic could either be directly recovered or further solidified via the $\mathrm{S} / \mathrm{S}$ process, depending on the actual need. From this point of view, it is more sustainable to generate metal arsenic from the solid waste, and thus can justify studying the reduction of arsenic in WSA into its elemental state as well as on other successive efforts (e.g., direct fixation of metal arsenic).

In recent decades, reports on arsenic preparation have all been about achieving its product grade [15-20]. While the market is not guaranteed, these routes may be too sophisticated to serve the purpose of waste minimization. Besides, over-emphasis on the recovery of arsenic has precluded the reclamation of other elements which should be able to partially cover the cost of the process.

The objective of this paper was to evaluate a process in which metal arsenic and sodium salts of potential commercial value were simultaneously obtained by thermal treatment of the WSA with charcoal powder. The charcoal powder was employed as the reducing agent because thermochemical calculation had suggested a simple process with only one step for this purpose. The generated sodium phases with a trace amount of arsenic consisted of mainly sodium carbonate and a little sodium oxide which obviously could be turned into the former by reacting with carbon dioxide. Factors affecting the process were investigated including flow rate of $\mathrm{N}_{2}$, dosage of charcoal powder, roasting temperature, and roasting time.

\section{Experiments}

\subsection{Materials}

The sodium arsenate used in this study was collected from Hunan Province, China. It was produced while separating arsenic from antimony in the AAR by water leaching. During the process, soluble arsenic species were dissolved into the aqueous phase, which was then boiled to obtain sodium arsenate. The sample was subjected to X-ray Fluorescence (XRF) (Bruker, Karlsruhe, Germany) to analyze its general elements and accurate analyses were conducted for the contents of arsenic and sodium. The results are shown in Table 1, indicating the crystals mainly consist of arsenic and sodium with minor impurities, such as $\mathrm{Fe}, \mathrm{Sb}, \mathrm{S}$, and so on.

The content of fixed carbon in the reducing agent, the charcoal powder, was analyzed to be $80.3 \mathrm{wt} \%$. Industrial grade $\mathrm{N}_{2}$ (purity $99.5 \%$ ) was used as protecting gas.

Table 1. The main compositions of the sample (\%).

\begin{tabular}{cccccccc}
\hline As & $\mathbf{N a}$ & $\mathbf{F e}$ & $\mathbf{S b}$ & $\mathbf{S}$ & $\mathbf{P}$ & $\mathbf{C a}$ & $\mathbf{A l}$ \\
\hline 16.79 & 16.82 & 0.016 & 0.086 & 0.075 & 0.34 & 0.1 & 0.041 \\
\hline
\end{tabular}




\subsection{Roasting Procedure}

The roasting procedure was conducted in a self-designed electric resistance furnace. The schematic illustration of the apparatus is shown in Figure 1. For each test, $10 \mathrm{~g}$ of the raw material was manually ground in a mortar along with certain amount of charcoal powder using a pestle to ensure good mixing. The mixture was then transferred into a corundum boat which had been pretreated by roasting for $2 \mathrm{~h}$ at $800{ }^{\circ} \mathrm{C}$.

The boat containing the sample was weighed and placed into the heating zone before the reactor (made of stainless steel 310s) was sealed with a removable lid. Protecting gas $\mathrm{N}_{2}$ was introduced into the container, and it was not until at least $5 \mathrm{~min}$ later that the heating started. The target temperature was achieved within $15 \mathrm{~min}$. After the sample was roasted for the required time, the removable lid was immediately discharged and the boat taken out to cool off under ambient conditions. It should be mentioned that, during the roasting process, the temperature fluctuated around the expected degree centigrade within $\pm 20^{\circ} \mathrm{C}$.

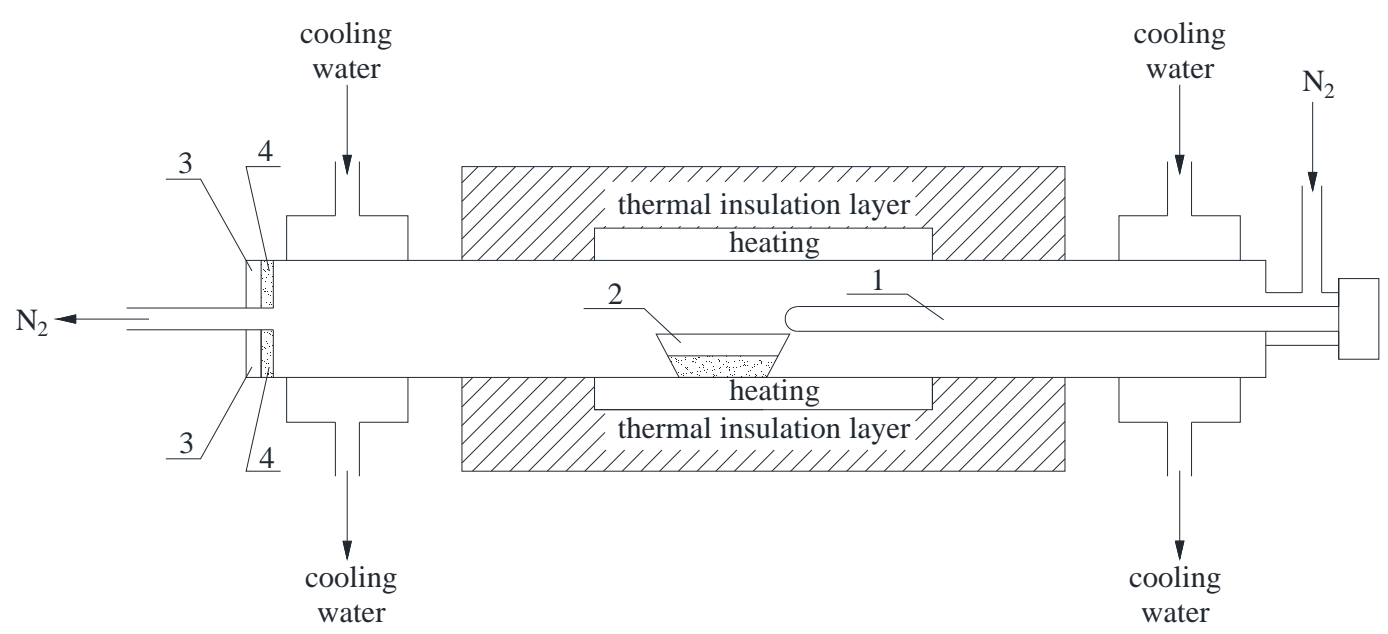

Figure 1. Experimental setup for the thermal treatment (1-Thermocouple; 2 -Corundum boat containing sample; 3 -Removable lid; 4-Condensed volatile product).

\subsection{Sample Preparation}

After cooling, some of the roasting products (especially those roasted at $900{ }^{\circ} \mathrm{C}$ ) had tightly cohered onto the surface of the boat, making it difficult to collect the entire sample. Therefore, in order to calculate the arsenic loss, the cooled boat along with the residue was directly immersed into nitric acid (30 wt \%) for the dissolution of the sample. The generated solution was stored in a sealed centrifuge tube before it was sent to Inductively Coupled Plasma-Atomic Emission Spectroscopy (ICP) (PerklinElmer, Waltham, MA, USA) for the assay of arsenic content. On the other hand, if the residue sample was needed, the experiment would be replicated and a screwdriver was used to scale off the solid as much as possible. In addition, volatile product was collected with care only from the internal surface of the removable lid because it was very difficult to take samples from other areas in the container without the introduction of many impurities, and since just a little amount of condensed phase was gathered in each run, it was evenly compiled to a mixture.

\subsection{Sample Analysis}

The content of fixed carbon in the charcoal powder was assayed by a Carbon/Sulfur Determinator (LECO CS844) (LECO Corporation, Saint Joseph, MO, USA). The arsenic contents of the solution and of the pooled volatile product were analyzed by ICP-AES (IRIS Interpid II XSP) (Thermo fisher scientific, Waltham, MA, USA). The solid sample was characterized by X-ray diffraction (XRD, Bruker AXS D8 Advance, Karlsruhe, Germany), and its morphology was observed by scanning electron micrograph 
(SEM, JSM-6360LV) (JEOL, Akishima, Japan). X-ray photoelectron spectroscopy (XPS) measurements were carried out on a Thermo Fisher Scientific K-Alpha 1063 (Waltham, MA, USA) using Al-K $\alpha$ X-ray as the excitation source, and the thermogravimetric analysis was conducted using a STA449F3A-0488M instrument (Netzsch, Bavaria, Germany).

\section{Results and Discussion}

\subsection{Sample Characteristics}

The phase compositions of the sample were analyzed by XRD and XPS and the results are presented in Figures 2 and 3, respectively.

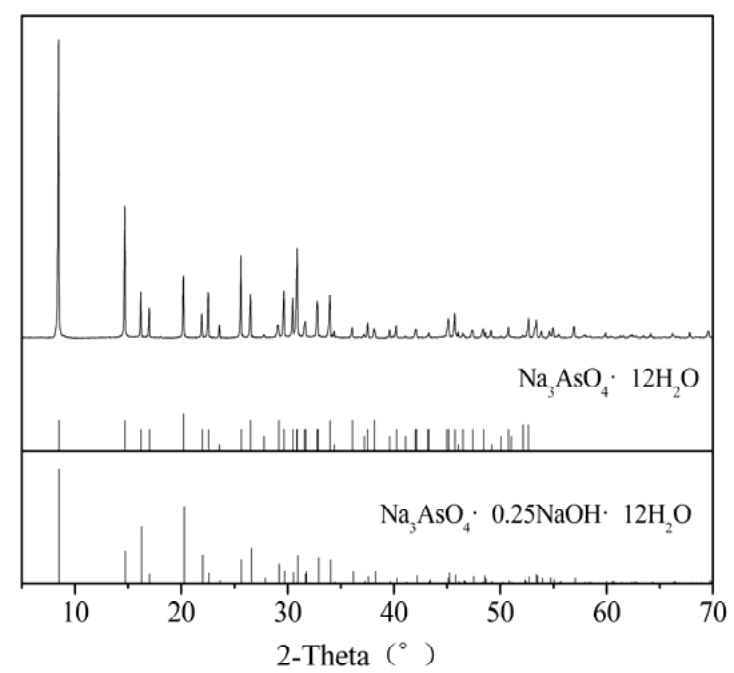

Figure 2. X-ray diffraction (XRD) pattern of the sample.
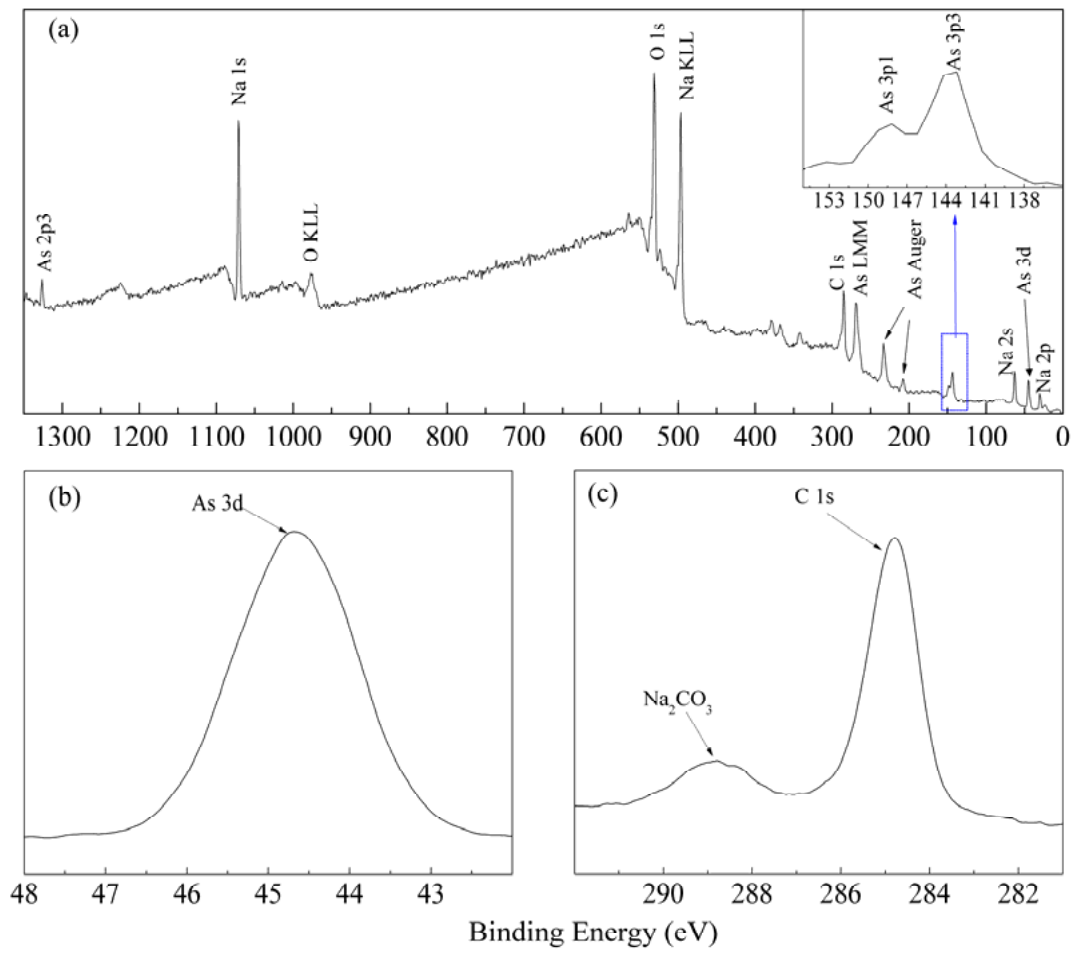

Figure 3. X-ray photoelectron spectroscopy (XPS) results of the sample (a) wide scan spectrum for the sample; (b) high-resolution scan for As 3d; (c) high-resolution scan for C 1 s. 
It can be found from Figure 1 that although different in intensities, the characteristic peaks of the sample has been distributed in similar locations in comparison to $\mathrm{Na}_{3} \mathrm{AsO}_{4} \cdot 12 \mathrm{H}_{2} \mathrm{O}(\mathrm{NH})$, $\mathrm{Na}_{3} \mathrm{AsO}_{4} \cdot 0.25 \mathrm{NaOH} \cdot 12 \mathrm{H}_{2} \mathrm{O}(\mathrm{NNH})$. This probably suggests the sample is the mixture of $\mathrm{NH}$ and $\mathrm{NNH}$. The difference in peak intensities between the sample and the standards could probably be accounted for by preferred orientation of the crystals which occurred during the preparation of sodium arsenate at industrial level.

The XPS wide scan spectrum is presented in Figure 3a, and peaks attributed to arsenic can be clearly seen including As 2p3, As 3p3, As 3p1, and As 3d at $1326 \mathrm{eV}, 143 \mathrm{eV}, 148 \mathrm{eV}$, and $45 \mathrm{eV}$, respectively [21,22]. In addition, peaks at 268, 232, $208 \mathrm{eV}$ could be assigned to As Auger lines [22]. Significant peaks corresponding to $\mathrm{O} 1 \mathrm{~s}, \mathrm{C} 1 \mathrm{~s}$, and $\mathrm{Na}$ 1s are also observed. Other elements which were found by XRF could not be detected by XPS due likely to their low contents. As reported [22-24], the binding energy of As $3 \mathrm{~d}$ has actually been indicative of the oxidation states of arsenic, with a value of $44 \mathrm{eV}$ and $45 \mathrm{eV}$ for $\mathrm{As}(\mathrm{III})$ and $\mathrm{As}(\mathrm{V})$, respectively. Figure $3 \mathrm{~b}$ has shown the high-resolution scan of As 3d, which gives a binding energy of $44.7 \mathrm{eV}$. The peak shape suggests the presence of a single valence, and not a contribution of multiple valences [25], which means As (V) is the only phase in the sample. On the other hand, detailed spectrum of $C 1 \mathrm{~s}$ is shown in Figure 3c. It can be noted that besides the main peak of $C 1 \mathrm{~s}$ located at $284.8 \mathrm{eV}$, a small peak is also observable at $289 \mathrm{eV}$. This could be assigned to sodium carbonate [26], although XRD has failed to reveal the presence of sodium carbonate.

\subsection{Thermal Gravity Analysis}

The sample with/without the addition of $12 \mathrm{wt} \%$ charcoal powder was subjected to thermal gravity analysis. This was conducted because it could reveal the temperature where the system endured mass changes, which is informative for the following experiments. The results are demonstrated in Figure 4.

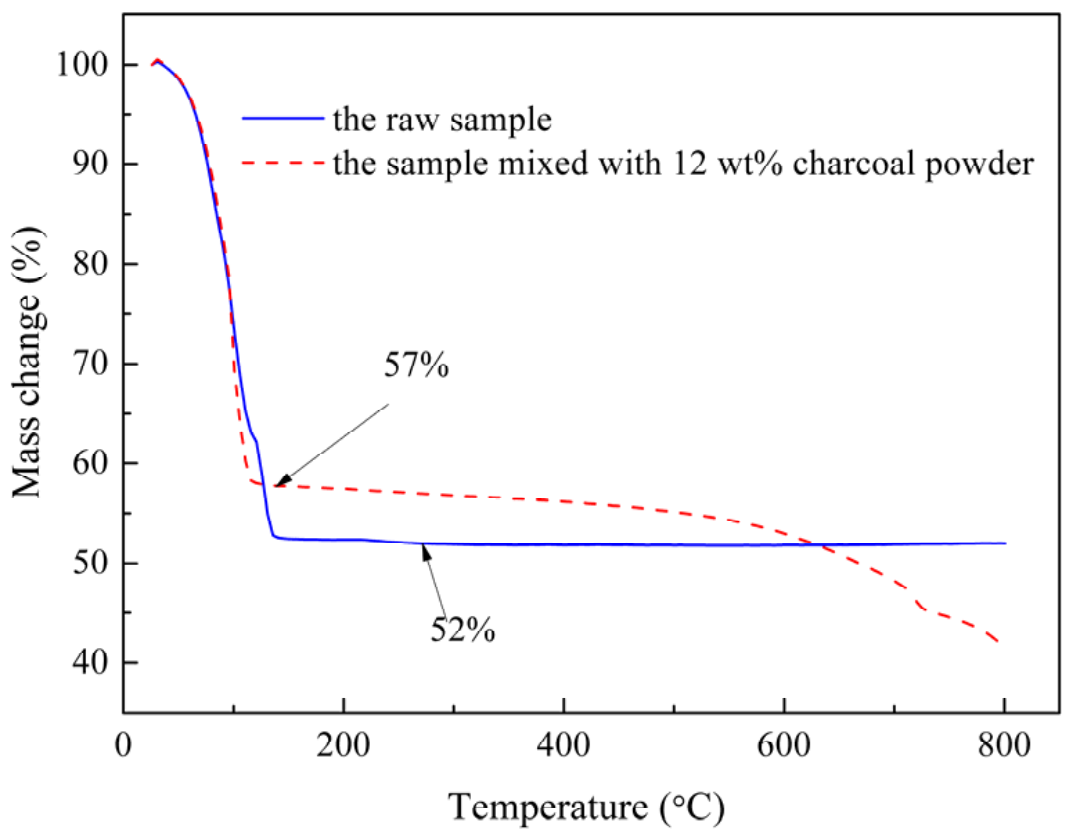

Figure 4. TG curve for sample with/without addition of charcoal powder (sample mass: 17.3/17.5 mg for sample with/without mixing with charcoal powder, respectively; temperature acceleration: $5^{\circ} \mathrm{C} / \mathrm{min}$; protecting gas: Ar at velocity of $20 \mathrm{~mL} / \mathrm{min}$ ).

As can be seen, the mass of both samples started to decrease almost immediately with the increase of temperature. 
For the sample without charcoal powder, a sharp mass reduction was observed at temperatures ranging from $30^{\circ} \mathrm{C}$ to $135^{\circ} \mathrm{C}$, which, in consistence with results indicated by Zhao et al. [27], could be explained by the evaporation of crystal water:

$$
\mathrm{Na}_{3} \mathrm{AsO}_{4} \cdot 12 \mathrm{H}_{2} \mathrm{O}=\mathrm{Na}_{3} \mathrm{AsO}_{4}+12 \mathrm{H}_{2} \mathrm{O}(\mathrm{g})
$$

Due to the impurities in the sample, the mass ratio remains about $52 \%$ instead of the reported $49.05 \%$ [27]. Meanwhile, taking into account the presence of $\mathrm{NNH}$, the following reaction could also happen:

$$
\mathrm{Na}_{3} \mathrm{AsO}_{4} \cdot 0.25 \mathrm{NaOH} \cdot 12 \mathrm{H}_{2} \mathrm{O}=\mathrm{Na}_{3} \mathrm{AsO}_{4}+0.25 \mathrm{NaOH}+12 \mathrm{H}_{2} \mathrm{O}(\mathrm{g})
$$

For the sample with charcoal powder, an approximate mass loss of $43 \%$ was found when the temperature was increased from $30^{\circ} \mathrm{C}$ to $125^{\circ} \mathrm{C}$. Apparently, this could also be accounted for by the dehydration of sodium arsenate. Given that the addition of charcoal powder is $12 \mathrm{wt} \%$ with respect to the raw sample, a calculation could be done to confirm that all the crystal water had been evaporated. Therefore, the other significant mass reduction, which was not initiated until the system was heated to $600{ }^{\circ} \mathrm{C}$, actually indicated the occurrence of related reactions without the involvement of vapor.

\subsection{Thermodynamic Consideration}

Based on TG results, thermochemical calculation was then carried out to reveal reactions causing the mass loss, and most importantly, to evaluate the possibility of direct conversion of sodium arsenate into free element arsenic. Using Outotec's Chemical Reaction and Equilibrium Software HSC Chemistry (Version 6.0, Espoo, Finland), changes of standard Gibbs free energy $\Delta_{\mathrm{r}} \mathrm{G}_{\mathrm{m}}^{\ominus}(\mathrm{T}, 1 \mathrm{bar}$ ) of concerned reactions during the roasting process were calculated.

Thermochemical data of sodium-arsenic phases at high temperature is barely found in the literature. The valid temperature range provided by this software is from $298 \mathrm{~K}$ (about $25^{\circ} \mathrm{C}$ ) to $1000 \mathrm{~K}$ (about $727^{\circ} \mathrm{C}$ ) for the calculation of dehydrated sodium arsenate (written as $\mathrm{Na}_{6} \mathrm{Aa}_{2} \mathrm{O}_{8}$ or $3 \mathrm{Na}_{2} \mathrm{O} \cdot \mathrm{As}_{2} \mathrm{O}_{5}$ ). Therefore, the computation was carried out at temperature ranging from $400{ }^{\circ} \mathrm{C}$ to $700{ }^{\circ} \mathrm{C}$. Correspondingly, the objective reactions are listed as follows:

$$
\begin{gathered}
2 \mathrm{Na}_{6} \mathrm{As}_{2} \mathrm{O}_{8}+5 \mathrm{C}=5 \mathrm{Na}_{2} \mathrm{CO}_{3}+\mathrm{Na}_{2} \mathrm{O}+\mathrm{As}_{4}(\mathrm{~g}) \\
2 \mathrm{Na}_{6} \mathrm{As}_{2} \mathrm{O}_{8}+10 \mathrm{C}=6 \mathrm{Na}_{2} \mathrm{O}+10 \mathrm{CO}(\mathrm{g})+\mathrm{As}_{4}(\mathrm{~g}) \\
2 \mathrm{Na}_{6} \mathrm{As}_{2} \mathrm{O}_{8}+5 \mathrm{C}=6 \mathrm{Na}_{2} \mathrm{O}+5 \mathrm{CO}_{2}(\mathrm{~g})+\mathrm{As}_{4}(\mathrm{~g})
\end{gathered}
$$

Meanwhile, since the generation of arsenic trioxide, another volatile phase for arsenic, would affect the purity of metal arsenic, the relevant reactions are also of interest:

$$
\begin{gathered}
2 \mathrm{Na}_{6} \mathrm{As}_{2} \mathrm{O}_{8}+2 \mathrm{C}=2 \mathrm{Na}_{2} \mathrm{CO}_{3}+4 \mathrm{Na}_{2} \mathrm{O}+\mathrm{As}_{4} \mathrm{O}_{6}(\mathrm{~g}) \\
2 \mathrm{Na}_{6} \mathrm{As}_{2} \mathrm{O}_{8}+4 \mathrm{C}=4 \mathrm{CO}(\mathrm{g})+6 \mathrm{Na}_{2} \mathrm{O}+\mathrm{As}_{4} \mathrm{O}_{6}(\mathrm{~g}) \\
2 \mathrm{Na}_{6} \mathrm{As}_{2} \mathrm{O}_{8}+2 \mathrm{C}=2 \mathrm{CO}_{2}(\mathrm{~g})+6 \mathrm{Na}_{2} \mathrm{O}+\mathrm{As}_{4} \mathrm{O}_{6}(\mathrm{~g})
\end{gathered}
$$

Accordingly, results of the calculations are demonstrated in Figure 5.

It can be seen that values of $\Delta_{\mathrm{r}} \mathrm{G}_{\mathrm{m}}^{\theta}$ of Equation (2)-(6) is far larger than $0 \mathrm{KJ} / \mathrm{mol}$ within the temperature range investigated, while that of Equation (1) becomes negative at about $500{ }^{\circ} \mathrm{C}$ and keeps decreasing. Therefore, the spontaneous formation of volatile arsenic trioxide during the reductive roasting of sodium arsenate is thermodynamically denied, indicating that the only possibility of the gaseous arsenic product is free element arsenic in the form of $\mathrm{As}_{4}(\mathrm{~g})$. Probably due to kinetic reasons, the reaction described by Equation (1) was not obvious enough to be observed until the temperature was increased to about $600{ }^{\circ} \mathrm{C}$, as indicated in Figure 4, instead of the calculated $500{ }^{\circ} \mathrm{C}$. 


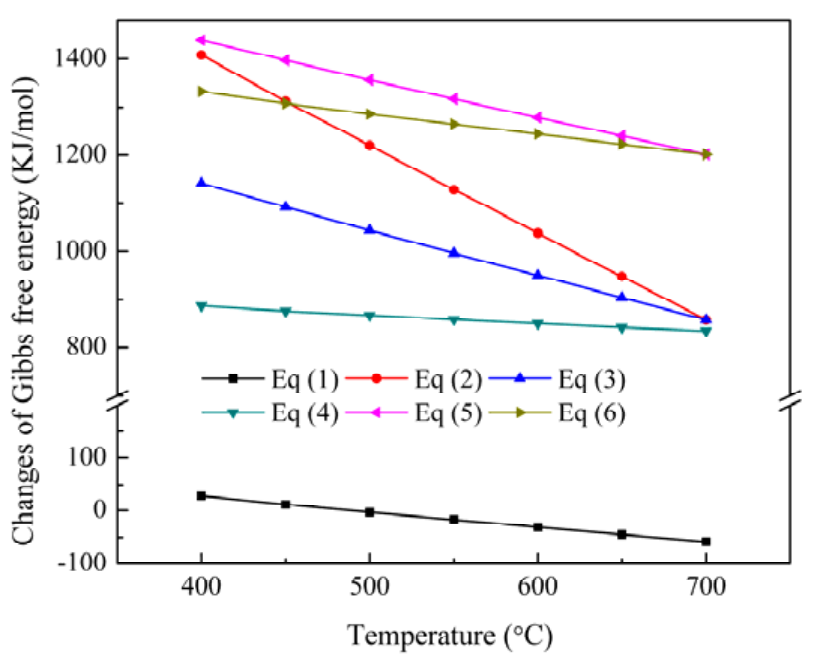

Figure 5. Changes of Gibbs free energy for concerned reactions

\subsection{Roasting Experiments}

One thing that should firstly be mentioned is that in order to confirm the reliability of the results, some experiments were randomly chosen and repeated three times, and the mean values of these results along with their standard deviations are presented in the related figures.

\subsubsection{Effects of $\mathrm{N}_{2}$ Flow Rate}

The effects of $\mathrm{N}_{2}$ flow rate on arsenic removal were studied in the preliminary experiment and the results are shown in Figure 6. Theoretically, larger $\mathrm{N}_{2}$ flow rate is favorable for arsenic volatilization because it could accelerate the escape of the product from the reaction system, which is helpful for the forward reaction.

As seen in Figure 6, without $\mathrm{N}_{2}$, the arsenic removal efficiency had already reached $93.07 \%$. When the gas was introduced into the system and the flow rate was set at $0.5 \mathrm{~L} / \mathrm{min}$, about $96.26 \%$ of arsenic could be removed. However, further increasing the $\mathrm{N}_{2}$ to $1.0 \mathrm{~L} / \mathrm{min}$ promoted arsenic volatilization only to $97.38 \%$. Taking into account the standard deviations, the improvement of arsenic extraction by increasing the $\mathrm{N}_{2}$ flow rate from $0.5 \mathrm{~L} / \mathrm{min}$ to $1.0 \mathrm{~L} / \mathrm{min}$ is negligible and the results should be considered to be at the same level. Therefore, in the following experiments, the $\mathrm{N}_{2}$ flow rate was fixed at $0.5 \mathrm{~L} / \mathrm{min}$.

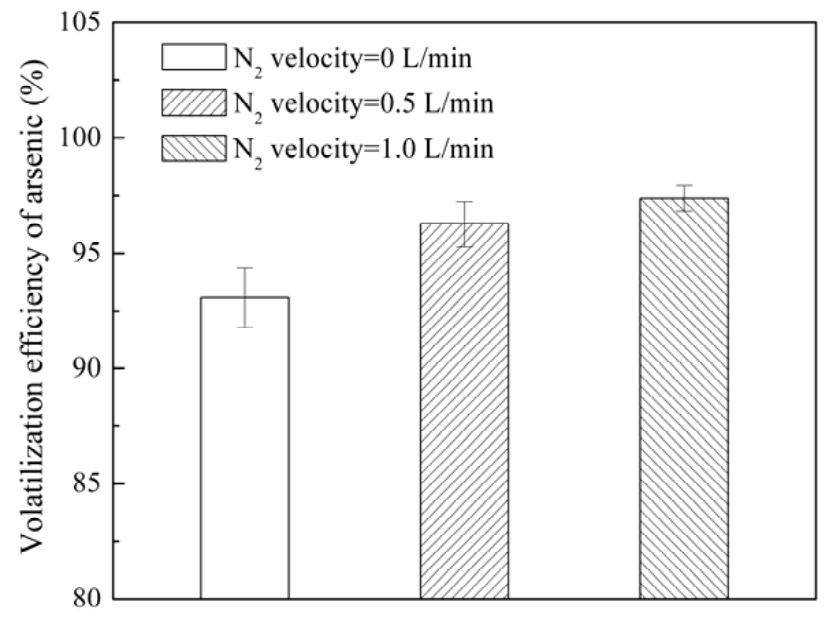

Figure 6. Effects of $\mathrm{N}_{2}$ flow rate on arsenic volatilization (dosage of charcoal powder: 8 wt \%; roasting temperature: $800{ }^{\circ} \mathrm{C}$; roasting time: $60 \mathrm{~min}$ ). 


\subsubsection{Effects of Temperature}

Figure 7 shows the effects of roasting temperature on arsenic extraction, and it can be seen that at all dosages of charcoal powder, arsenic extraction was pronouncedly promoted by elevating the temperature within the range of $600-800{ }^{\circ} \mathrm{C}$. For example, when $8 \%$ was consumed, the arsenic extraction was $79.56 \%$ at $600{ }^{\circ} \mathrm{C}$, and it was increased to $96.26 \%$ at $800{ }^{\circ} \mathrm{C}$. However, temperature higher than $800{ }^{\circ} \mathrm{C}$ seemed to have adverse effects on the process. Arsenic removal was decreased for all samples when the temperature was further increased to $900{ }^{\circ} \mathrm{C}$, namely, it had dropped to $93.94 \%$ for the abovementioned sample. The reason was unclear, but it was observed that the higher the temperature, the more compact the roasting product was and the tighter it had cohered onto the surface of the corundum boat. Meanwhile, the residue was more transparent at $900{ }^{\circ} \mathrm{C}$, meaning the vitreous phase was formed during the cooling process. These observations indicate that higher temperature helps the sample to melt completely. Therefore, the decrease in arsenic extraction was probably caused by the viscosity of the melt, which had, to some extent, hindered the evaporation of arsenic.

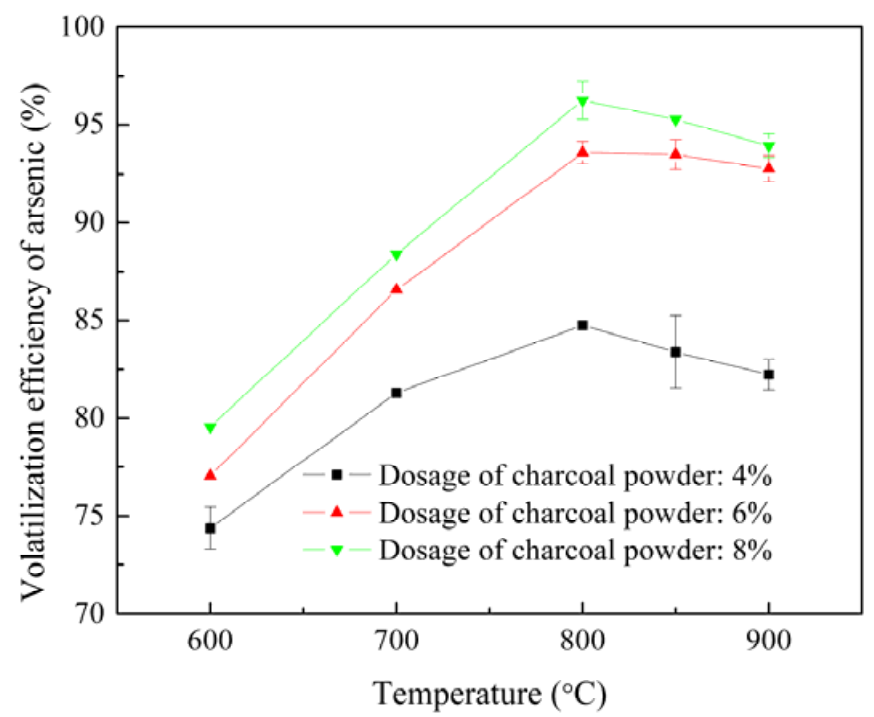

Figure 7. Effects of roasting temperature on arsenic volatilization under different dosages of charcoal powder (roasting time: $60 \mathrm{~min}$ ).

\subsubsection{Effects of Charcoal Powder Dosage}

In order to further improve the arsenic extraction, effects of the dosage of charcoal powder under different temperatures were investigated. As shown in Figure 8, arsenic removal had apparently depended on the amounts of the reductant added into the system. More charcoal powder was beneficial for extracting arsenic from the sample. The arsenic removal had almost reached $100 \%$ (exactly, 99.84\%) with $12 \%$ addition of the charcoal powder by roasting the sample at $800{ }^{\circ} \mathrm{C}$ for $60 \mathrm{~min}$. At this point, it should be reported that arsenic content in the roasting product had correspondingly decreased to $0.0598 \%$. In comparison, only $92.07 \%$ of arsenic was extracted at $700{ }^{\circ} \mathrm{C}$ and the arsenic grade in the residue was $3.24 \%$ after roasting for $60 \mathrm{~min}$ with $12 \%$ charcoal powder.

On the other hand, it was calculated before the experiments that, stoichiometrically according to Equation (1), about $4.2 \%$ of charcoal powder is needed for the complete reduction of As (V) into As (0) in the sample. However, Figure 8 shows that the results barely reached $90 \%$ with $4 \%$ of the reductant. Although results of thermal gravity indicated that the sample loses its crystal water at $35-135^{\circ} \mathrm{C}$ (Figure 4), the temperature acceleration may be so quick as not to leave enough time for the vapor to totally escape from the system. Therefore, one possible explanation is that the carbon was partially consumed by the formed vapor through reaction: $\mathrm{C}+\mathrm{H}_{2} \mathrm{O}(\mathrm{g})=\mathrm{CO}(\mathrm{g})+\mathrm{H}_{2}(\mathrm{~g})$. 


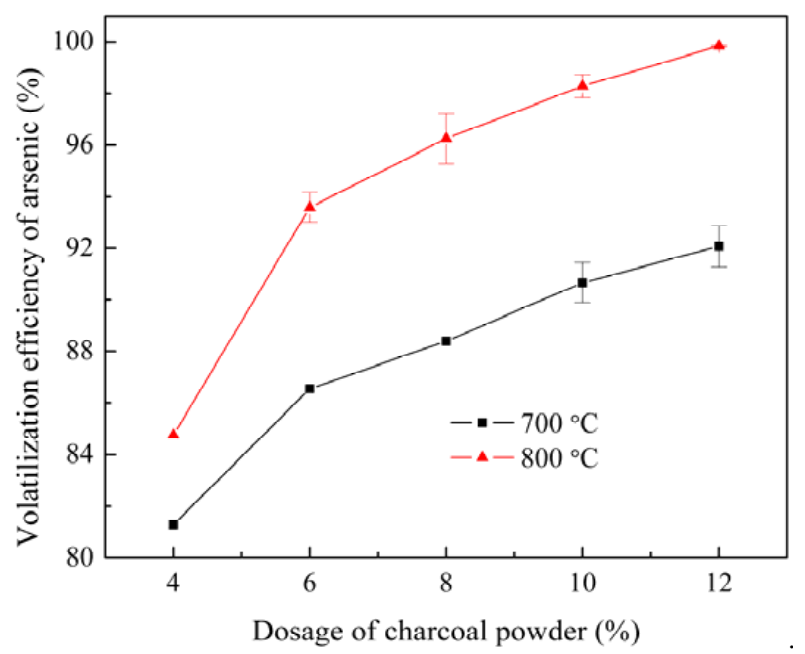

Figure 8. Effects of charcoal powder dosage on arsenic volatilization under different temperatures (roasting time: $60 \mathrm{~min}$ ).

\subsubsection{Effects of Roasting Time}

Figure 9 shows the effects of roasting time on arsenic removal at $800{ }^{\circ} \mathrm{C}$. It can be seen that the process happened very fast. For the cases investigated, more than $90 \%$ of arsenic was extracted within $30 \mathrm{~min}$. Further increasing the roasting time had comparably only improved the arsenic extraction a little. For the sample with $6 \%$ charcoal powder, arsenic extraction had not reached $99.0 \%$ after a 150 min thermal treatment. In comparison, with the addition of $8 \%$ charcoal powder, the arsenic removal achieved $99.43 \%$ when the sample was roasted for $120 \mathrm{~min}$.

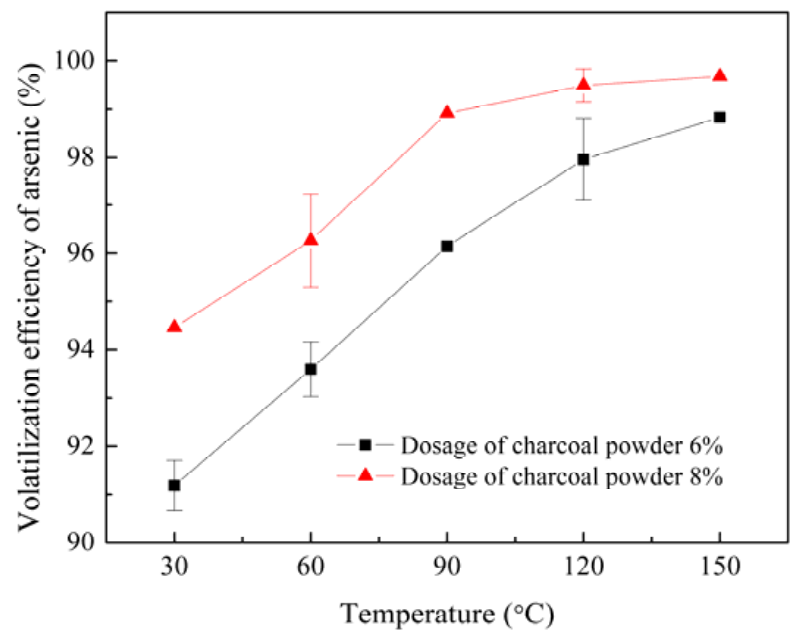

Figure 9. Effects of roasting time on arsenic volatilization under different dosages of charcoal powder (roasting temperature: $800^{\circ} \mathrm{C}$ ).

\subsection{Analyses on the Roasting Residues and the Volatile Products}

Some experiments were repeated to collect the residues which were then subjected to XRD and XPS in order to reveal more details of the roasting process. Related observations should be mentioned before the results are presented: (1) the residues were found to be hygroscopic, making it impossible to achieve the expected fineness because some particles could easily be either ground onto the surface of mortar or compacted together; (2) although the samples were dried at $105{ }^{\circ} \mathrm{C}$ prior to the XRD procedure, irregular changes on diffraction angle were still detected because of the deliquescence, so the XRD did not proceed until the diffraction stopped deviating. 


\subsubsection{Roasting Residues}

Figure 10 shows the results of XRD for the roasting residues. First of all, the presence of $\mathrm{Na}_{2} \mathrm{CO}_{3}$ and/or $\mathrm{Na}_{2} \mathrm{CO}_{3} \cdot \mathrm{H}_{2} \mathrm{O}$ in all the samples was confirmed. However, there is no evidence for the generation of $\mathrm{Na}_{2} \mathrm{O}$ or $\mathrm{NaOH}$. Secondly, arsenic salts including $\mathrm{Na}_{3} \mathrm{AsO}_{4} \cdot 12 \mathrm{H}_{2} \mathrm{O}$ and $\mathrm{Na}_{3} \mathrm{AsO}_{4} \cdot 0.25 \mathrm{NaOH} \cdot 12 \mathrm{H}_{2} \mathrm{O}$ are found in samples $\mathrm{B}$ and C. Since previous results has suggested that arsenic extractions were $96.26 \%$ and $77.04 \%$ for samples B and C, respectively, it is unsurprising to make this observation. Meanwhile, the hydration of these phases is also accountable because, as mentioned before, the sample had been deliquesced. Finally, there were no arsenic phases detected in sample A. Given the fact that only $0.0598 \%$ of arsenic is left in the residue, it is reasonable that the trace phase is difficult to detect. This could again be proved by XPS results, as shown in Figure 11, where it was found that the characteristic peaks of arsenic disappeared in sample A while they were still detectable in sample B. The narrow scan of As $3 \mathrm{~d}$ further confirmed this observation.

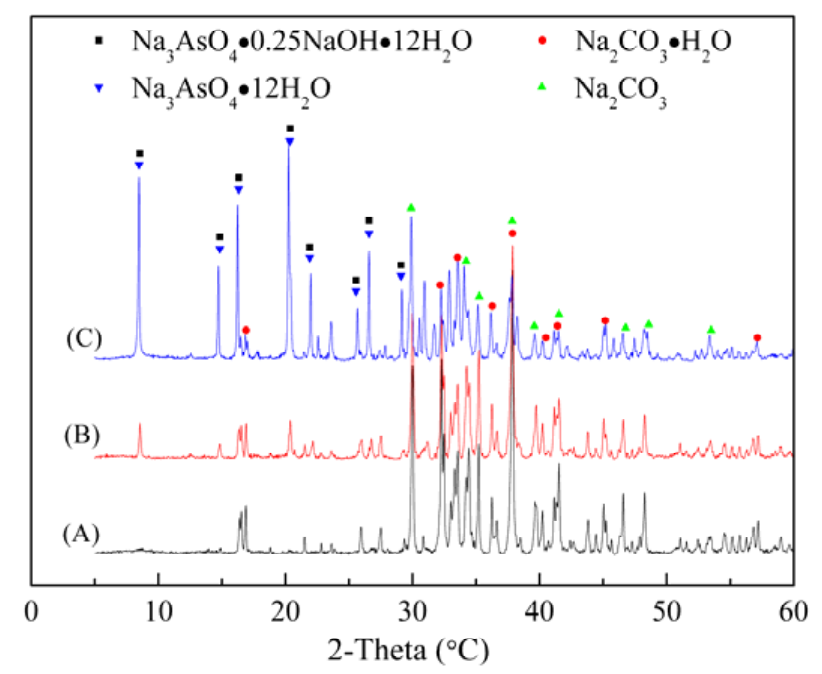

Figure 10. XRD results of the roasting residues (A: sample roasted at $800{ }^{\circ} \mathrm{C}$ for 60 min with $12 \%$ charcoal powder; B: sample roasted at $800{ }^{\circ} \mathrm{C}$ for $60 \mathrm{~min}$ with $8 \%$ charcoal powder; C: sample roasted at $600{ }^{\circ} \mathrm{C}$ for $60 \mathrm{~min}$ with $6 \%$ charcoal powder).

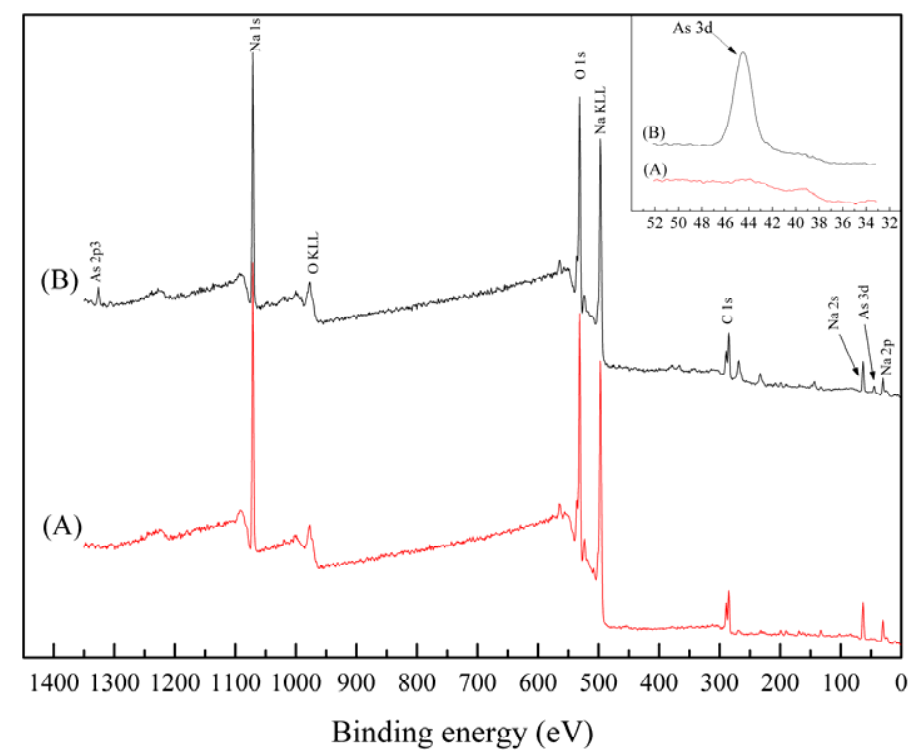

Figure 11. XPS narrow scan for As $3 \mathrm{~d}$ of the roasting residues (A: sample roasted at $800{ }^{\circ} \mathrm{C}$ for $60 \mathrm{~min}$ with $12 \%$ charcoal powder; B: sample roasted at $800{ }^{\circ} \mathrm{C}$ for $60 \mathrm{~min}$ with $8 \%$ charcoal powder). 


\subsubsection{Volatile Product}

The collected volatile product, which turned out to be black powder, was assayed by ICP, indicating its arsenic content had reached $97.3 \%$. The SEM image revealed the presence of countless spherical granules and of a few crystal-like particles in the product (Figure 12a). The sizes of these particles are small (less than $5 \mu \mathrm{m}$ ) and the irregular ones tended to be agglomerated with each other. Further in Figure 12b, the XRD pattern shows multiple broad peaks, suggesting these particles are amorphous. However, some of the characteristic peaks of arsenolamprite (PDF\#85-1712, chemical formula: As) do fit into the ranges of the broad peaks although it is impossible to identify their $d$ values. This may suggest that related crystal faces on these directions were poorly formed. It is explainable since when the temperature is rapidly decreased for the desublimation of the gaseous phase, it usually leaves no time for thorough crystallization.
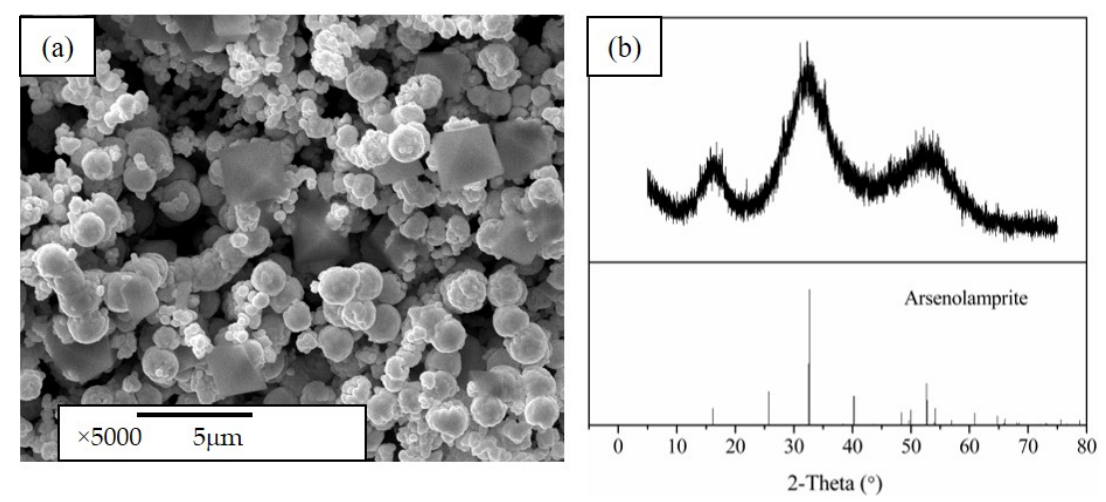

Figure 12. Scanning electron micrograph (SEM) image and XRD pattern of the volatile product.

Figure 13 shows the XPS spectra of the volatile product. As shown in Figure 13a, besides peaks for arsenic, carbon, and oxygen, there are no other lines found. In addition, As Auger lines at 226, $262,336,360$, and $371 \mathrm{eV}$ are clearly demonstrated (Figure 13b). The most sound evidence for the formation of metal arsenic can be found in Figure 13c, where high-resolution of the peak As $3 \mathrm{~d}$ is presented. It perfectly matched the reported binding energies of 41.6 and $42.3 \mathrm{eV}$ for As $3 \mathrm{~d} 5$ and As $3 \mathrm{~d} 3$, respectively [28]. On the other hand, a small peak is found at $45.2 \mathrm{eV}$ and is attributed to $\mathrm{As}_{2} \mathrm{O}_{3}$ [28], which must be formed due to surface oxidation of the particles.

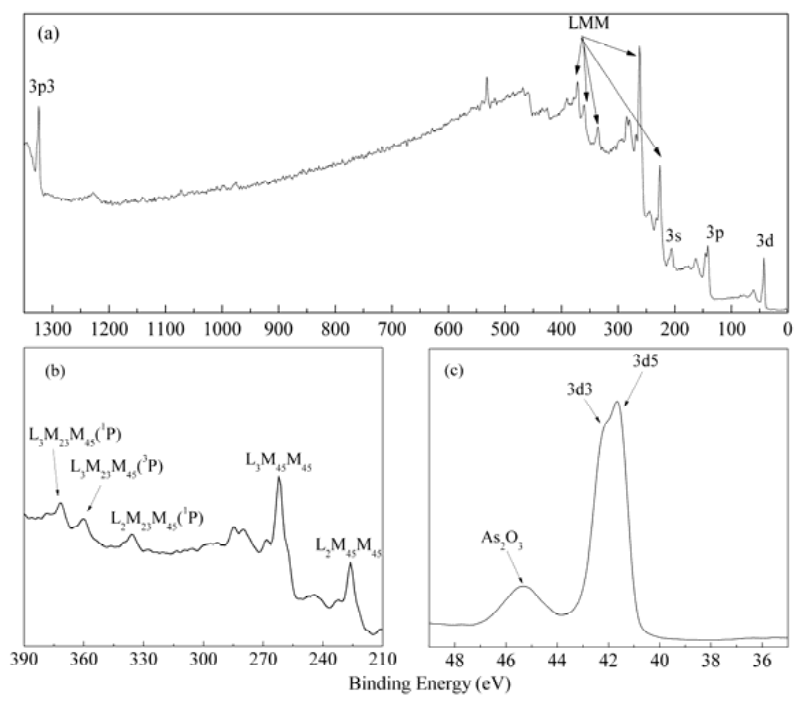

Figure 13. XPS details of the volatile product (a) wide scan of the volatile product; (b) details on the Auger spectrum; (c) narrow scan for As 3d. 
Based on the discussion above, reaction Equation (1) must have occurred during the reductive roasting process of sodium arsenate with charcoal powder even though there is no direct evidence for the formation of sodium oxide (more accurately speaking, the phase to be detected should be sodium hydroxide as sodium oxide was exposed in the air and therefore ready to be attacked by moisture).

\section{Conclusions}

The present paper has for the first time proved it is feasible to reductively decompose waste sodium arsenate (WSA) by thermal treatment with charcoal powder, serving the purpose of waste minimization and simultaneous exploitation of its potential commercial value. Based on the results and discussion above, the following conclusions were drawn:

(1) $99.84 \%$ of arsenic could be separated after the waste was roasted at $800{ }^{\circ} \mathrm{C}$ for $60 \mathrm{~min}$ with charcoal powder dosage $12 \%$;

(2) The roasting residue containing only a little arsenic (exactly, 0.0598 wt \%) was comprised of sodium salts, mainly $\mathrm{Na}_{2} \mathrm{CO}_{3}$. Therefore, it was a prospective source for the production of $\mathrm{Na}_{2} \mathrm{CO}_{3}$;

(3) The reaction $2 \mathrm{Na}_{6} \mathrm{As}_{2} \mathrm{O}_{8}+5 \mathrm{C}=5 \mathrm{Na}_{2} \mathrm{CO}_{3}+\mathrm{Na}_{2} \mathrm{O}+\mathrm{As}_{4}(\mathrm{~g})$ accounted for the reduction of $\mathrm{As}(\mathrm{V})$ and the volatilization of metal arsenic, and no other unwanted arsenic phase was volatilized;

(4) The collected metal arsenic was ready for further purification and/or safe disposal, depending on the actual need.

Accordingly, the proposed route could minimize WSA and exploit the potential commercial value of the waste at the same time.

Author Contributions: Conceptualization, W.L. and W.Q.; Data Curation, K.Y.; Formal Analysis, K.Y.; Methodology, K.Y.; Project Administration, W.Q.; Supervision, W.Q.; Validation, W.L.; Writing-Original Draft Preparation, K.Y.; Writing-Review \& Editing, W.Q.

Funding: The authors gratefully acknowledge the financial support by Provincial Science and Technology Leader (Innovation team of interface chemistry of efficient and clean utilization of complex mineral resources) (Project No. 2016RS2016); Co-Innovation Centre for Clean and Efficient Utilization of Strategic Metal Mineral Resources and the Innovation Driven Plan of Central South University (Project No. 2015CX005).

Conflicts of Interest: The authors declare no conflict of interest.

\section{References}

1. Leist, M.; Casey, R.J.; Caridi, D. The fixation and leaching of cement stabilized arsenic. Waste Manag. (Oxf.) 2003, 23, 353-359. [CrossRef]

2. Fujita, T.; Taguchi, R.; Kubo, H.; Shibata, E.; Nakamura, T. Immobilization of Arsenic from Novel Synthesized Scorodite: Analysis on Solubility and Stability. Mater. Trans. 2009, 50, 321-331. [CrossRef]

3. Li, J.; Liang, H.Q. Treatment Strategies Study on the Comprehensive Utilization of Arsenic-alkali Residue in Xikuangshan Area. Hunan Nonferrous Met. 2010, 26, 53-54. (In Chinese)

4. Qiu, Y.H.; Lu, B.Q.; Chen, B.Z.; Zhong, Y.; Fu, W.; Yang, Y.Q. Commercial scale test of anti-pollution control technique for slag of arsenic and soda. J. Cent. South Univ. Technol. 2005, 36, 234-237. (In Chinese)

5. Li, H.; Zeng, G.S.; Shao, J.G.; Deng, X.R. Leaching kinetics and separation of antimony and selenium from arsenic alkali residue. Nonferrous Met. (Extr. Metall.) 2012, 3, 1-3. (In Chinese)

6. Clancy, T.M.; Hayes, K.F.; Raskin, L. Arsenic Waste Management: A Critical Review of Testing and Disposal of Arsenic-Bearing Solid Wastes Generated during Arsenic Removal from Drinking Water. Environ. Sci. Technol. 2013, 47, 10799-10812. [CrossRef] [PubMed]

7. Sullivan, C.; Tyrer, M.; Cheeseman, C.R.; Graham, N.J.D. Disposal of water treatment wastes containing arsenic-A review. Sci. Total Environ. 2010, 408, 1770-1778. [CrossRef] [PubMed]

8. Nazari, A.M.; Radzinski, R.; Ghahreman, A. Review of arsenic metallurgy: Treatment of arsenical minerals and the immobilization of arsenic. Hydrometallurgy 2017, 174, 258-281. [CrossRef]

9. Leist, M.; Casey, R.J.; Caridi, D. The management of arsenic wastes: problems and prospects. J. Hazard. Mater. 2000, 76, 125-138. [CrossRef] 
10. Yamasaki, N.; Zhang, F. A study on hydrothermal disposal of sodium arsenate waste from Ga-As processing. J. Mater. Sci. 1999, 34, 4017-4022. [CrossRef]

11. Paktunc, D.; Bruggeman, K. Solubility of nanocrystalline scorodite and amorphous ferric arsenate: Implications for stabilization of arsenic in mine wastes. Appl. Geochem. 2010, 25, 674-683. [CrossRef]

12. Mollah, M.Y.; Kesmez, M.; Cocke, D.L. An X-ray diffraction (XRD) and Fourier transform infrared spectroscopic (FT-IR) investigation of the long-term effect on the solidification/stabilization (S/S) of arsenic(V) in Portland cement type-V. Sci. Total Environ. 2004, 325, 255-262. [CrossRef] [PubMed]

13. Korte, N.E. A review of arsenic (III) in groundwater. Crit. Rev. Env. Sci. Technol. 1991, 21, 1-39. [CrossRef]

14. Dutré, V.; Vandecasteele, C.; Opdenakker, S. Oxidation of arsenic bearing fly ash as pretreatment before solidification. J. Hazard. Mater. 1999, 68, 205-215. [CrossRef]

15. Fedorov, V.A.; Churbanov, M.F. Ultrapure arsenic and its compounds for optical and semiconductor materials. Inorg. Mater. 2016, 52, 1339-1357. [CrossRef]

16. Fedorov, V.A.; Zhukov, E.G.; Nikolashin, S.V.; Potolokov, V.N.; Serov, A.V.; Smetanin, A.V. Sublimation Purification of Crude Arsenic Recovered from Nonferrous Waste. Inorg. Mater. 2001, 37, 1011-1016. [CrossRef]

17. Potolokov, V.N.; Efremov, V.A.; Zhukov, E.G.; Pashinkin, A.S.; Potolokov, N.A.; Fedorov, V.A. Preparation of High-Purity Arsenic via Hydrogen Reduction of Arsenic Trichloride. Inorg. Mater. 2003, 39, 15-21. [CrossRef]

18. Smetanin, A.V.; Pyshkin, A.S.; Osipov, G.N.; Sokhadze, L.A.; Smirnov, M.K.; Turygin, V.V.; Zhukov, E.G.; Potolokov, V.N.; Tomilov, A.P.; Fedorov, V.A. Arsenic extraction from nonferrous metals industry waste. Inorg. Mater. 2007, 43, 1093-1102. [CrossRef]

19. Smetanin, A.V.; Smirnov, M.K.; Chernykh, I.N.; Turygin, V.V.; Khudenko, A.V.; Fedorov, V.A.; Tomilov, A.P. Electrochemical Preparation of Arsenic and Its Compounds. Inorg. Mater. 2003, 39, 22-36. [CrossRef]

20. Turygin, V.V.; Smirnov, M.K.; Smetanin, A.V.; Zhukov, E.G.; Fedorov, V.A.; Tomiliov, A.P. Electrochemical arsenic extraction from nonferrous metals industry waste. Inorg. Mater. 2008, 44, 946-953. [CrossRef]

21. Peng, B.; Lei, J.; Min, X.B.; Chai, L.Y.; Liang, Y.J.; You, Y. Physicochemical properties of arsenic-bearing lime-ferrate sludge and its leaching behaviors. Trans. Nonferrous Met. Soc. China 2017, 27, 1188-1198. [CrossRef]

22. Groenewold, G.S.; Avci, R.; Fox, R.V.; Deliorman, M.; Suo, Z.Y.; Kellerman, L. Characterization of Arsenic Contamination on Rust from Ton Containers. Ind. Eng. Chem. Res. 2013, 52, 1396-1404. [CrossRef]

23. Bang, S.; Johnson, M.D.; Korfiatis, G.P.; Meng, X.G. Chemical reactions between arsenic and zero-valent iron in water. Water Res. 2005, 39, 763-770. [CrossRef] [PubMed]

24. Wang, S.; Mulligan, C.N. Speciation and Surface Structure of Inorganic Arsenic in Solid Phases: A Review. Eviron. Int. 2008, 34, 867-879. [CrossRef] [PubMed]

25. Martinson, C.A.; Reddy, K.J. Adsorption of arsenic(III) and arsenic(V) by cupric oxide nanoparticles. J. Colloid Interface Sci. 2009, 336, 406-411. [CrossRef] [PubMed]

26. Wagner, C.D.; Riggs, W.M.; Davis, L.E.; Moulder, J.F. Handbook of X-ray Photoelectron Spectroscopy; Perkin-Elmer Coporation, Physical Electronics Division: Eden Prairie, MN, USA, 1979.

27. Zhao, Z.W.; Song, Y.X.; Min, X.B.; Liang, Y.J.; Chai, L.Y.; Shi, M.Q. XPS and FTIR studies of sodium arsenate vitrification by cullet. J. Non-Cryst. Solids 2016, 452, 238-244. [CrossRef]

28. Moulder, J.F.; Stickle, W.F.; Spobol, P.E.; Bomben, K.D. Handbook of X-ray Photoelectron Spectroscopy; Phsical Electronics, Inc.: Eden Prairie, MN, USA, 1992.

(C) 2018 by the authors. Licensee MDPI, Basel, Switzerland. This article is an open access article distributed under the terms and conditions of the Creative Commons Attribution (CC BY) license (http:/ / creativecommons.org/licenses/by/4.0/). 